\title{
Kontruksi ldentitas melalui Stories Highlight Instagram Kalangan Kelas Menengah
}

\author{
Rama Kertamukti ${ }^{1}$, Heru Nugroho ${ }^{2}$, S. Bayu Wahyono ${ }^{3}$ \\ ${ }^{1}$ Mahasiswa Program Studi S3 Kajian Budaya dan Media Universitas Gadjah Mada, \\ ${ }^{1}$ Universitas Islam Negeri Sunan Kalijaga, \\ 2Program Studi Sosiologi Universitas Gadjah Mada, \\ ${ }^{3}$ Kurikulum dan Teknologi Pendidikan Universitas Negeri Yogyakarta \\ No.Hp +62085647530998 \\ Email: rama.mukti@uin-suka.ac.id, heru.slg@ugm.ac.id, sugeng_bw@uny.ac.id
}

\begin{abstract}
Instagram as a cyber commodity wants to unite and become an entity in the community lifestyle. Inter-human communication on Instagram can occur at any time during online connection, almost every user activity can be captured and published on Instagram in seconds. The production and consumption of messages happening on Instagram is done on Instagram Stories as a production of middle class status messages. This study aims to find identity construction through stories highlight Instagram. This study uses a qualitative method, examining how identity construction through Instagram Stories owned by Instagram by the middle class with informant accounts@putrilellyana,@rosakusumaazhar,@herni_maryuliani, @taufik.mbantul, @fajarmantoo.This research was conducted using virtual ethnography and independent interviews to explore data in order to get answers to research problems. Middle-class informants show that Instagram as a visual media is able to present certain symbols as a tool to produce meaning from an identity to be conveyed. The self presented by informants on Instagram Stories reflects leisure informants in carrying out activities freely in life such as hobbies, recreation, increasing knowledge about art and culture and also filling in actual activities for leisure time. Continuous research on codes, values, and beliefs about culture as a whole on Instagram needs to be explored to show the results of technology that is acculturated with economic, social and cultural factors.
\end{abstract}

Keywords: Instagram, Identity Construction, Instagram Stories

\begin{abstract}
Abstrak
Instagram sebagai komoditi dunia siber ingin menyatukan dan menjadi entitas bagian gaya hidup masyarakat. Komunikasi antar manusia dalam Instagram dapat terjadi setiap saat selama terhubungonline, hampir setiap aktivitas pengguna dapat diabadikan dan dipublikasikan ke dalam instagram dalam hitungan detik. Produksi maupun konsumsi pesan terjadi di Instagram dilakukan dalam Instagram Stories sebagai produksi pesan status kelas menengah. Penelitian ini bertujuan untuk menemukan konstruksi identitas melalui stories highlight Instagram. Penelitian ini menggunakan metode kualitatif, meneliti bagaimana kontruksi identitas melalui Instagram Stories yang dimiliki Instagram oleh kelas menengah dengan akun informan @putrilellyana, @rosakusumaazhar, @herni_maryuliani, @taufik.mbantul, @fajarmantoo. Penelitian ini dilakukan dengan menggunakan virtual etnografi dan indepth interview untuk menggali data agar dapat mendapatkan jawaban-jawaban atas permasalahan penelitian. Hasil penelitian menunjukkan bahwa informan kelas menengah menggunakan Instagram sebagai media visual yang mampu menghadirkan simbol-simbol sebagai alat memproduksi makna dari suatu identitas yang ingin disampaikan. Diri yang dihadirkan informan di Instagram Stories merefleksikan leisure informan dalam melakukan aktivitas secara bebas dalam hidup seperti hobi, rekreasi, menambah pengetahuan tentang seni dan budaya dan juga mengisi kegiatan-kegiatan aktual untuk mengisi waktu luang. Substansi penelitian ini yaitu menemukan metode virtual etnografi yang belum banyak dikaji. Penelitian berkelanjutan mengenai kode-kode, nilai-nilai, dan keyakinan atas kebudayaan secara keseluruhan atas Instagram perlu digali untuk memperlihatkan hasil teknologi yang berakulturasi dengan faktor-faktor ekonomi, sosial dan budaya.
\end{abstract}

Kata Kunci: Instagram, Kontruksi Identitas, Instagram Stories 


\section{Pendahuluan}

Media sosial menggunakan teknologi berbasis web mengubah komunikasi menjadi sebuah ruang dialogis tanpa henti selama tersambung server, tiap entitas dapat membuat, menyunting, publikasi, berpromosi, dan mengunggah foto maupun video yang dikehendaki, dengan pengembangan aplikasi yang menghadirkan keefektifan, efisiensi, cepat, interaktif dan variatif. Media sosial membuka ruang dalam berhubungan berinteraksi antar pemilik komputer, membuka ruang berbagi offline menjadi berjejaring online, dan menciptakan praktik konsumsi-produksi pesan.

Instagram sebagai komoditi dunia siber ingin menyatukan dan menjadi entitas ini sebagai bagian gaya hidup masyarakat, keterhubungan antar Instagramers (pengguna Instagram). Komunikasi antar manusia dalam Instagram dapat terjadi setiap saat selama terhubung-online, hampir setiap aktivitas pengguna dapat diabadikan dan dipublikasikan ke dalam instagram dalam hitungan detik. Keefektifan, efisiensi, cepat, interaktif dan variatif menjadi andalan Instagram. Media sosial ini mengejar para pesaing seperti Facebook, maupun Twitter sebelumnya telah hadir mengisi ruang online untuk berinteraksi. Instagram memacu aplikasinya menghadirkan berbagi foto (photo sharing) di aktivitas kendali aplikasi interaksi ini. Instagram mulai menjadi primadona seiring makin mudahnya menangkap momen-momen dengan berbagai perangkat fotografi yang disediakan dalam gadget milik pengguna yang menanam aplikasi Instagram. Selain mudah dan simple, dengan berbagi gambar atau foto sebenarnya tidak hanya menunjukkan apa yang sedang dilihat, kerjakan atau rasakan namun lebih dari itu bisa menyampaikan pesan di dalamnya. Di dalam Instagram foto dilekati tanda yang dapat berfungsi sebagai petanda dan penanda sekaligus dalam narasi foto pengguna dan dimaknai oleh si pengikut merekanarasi dalam ruang yang dihadirkan, sehingga ruang artikulasi makna keduanya dapat melebur dalam ruang offline-online.

Sadar ataupun tidak, realitas virtual yang dihadirkan dalam Instagram ini membuat semakin mudah dan murah memberikan kontribusi yang signifikan bagi realitas virtual. Seolah-olah dapat dikatakan bahwa entitas menjadi terikat dalam dunia virtual. Entitas ini menjadikan dunia offline-online tidak hanya terhubung secara parallel, tetapi melebur dan menyatu (Boellstorff, Nardi, Pearce, \& Taylor, 2012:1). Instagram menjadi ruang pamer foto, menjadi semacam ruang pribadi karena galeri pengguna bisa didesain sedemikian rupa sesuai kehendak pengguna, pengguna mengunggah apa saja yang terjadi di sekitar pengguna, yang dianggap mewakili aktivitas pengguna. Kadangkala motif untuk mengunggah teks berupa caption, foto atau gambar, suara tidak secara jelas ditujukan kepada siapa. Komunikasi menjadi tidak bisa dijelaskan kepada siapa yang terlibat di dalamnya atau kepada siapa teks berupa caption, foto atau gambar, dan suara itu ditujukan.

Pengguna Instagram adalah bagian dari masyarakat yang ingin berbagi dan memiliki konsep diri untuk memerankan peran-peran tertentu dalam masyarakat. Harapan yang 
dipengaruhi lingkungan dihadirkan dengan intepretasi melalui identitas. Intepretasi itu dengan cara mencitrakan sesuatu, perilaku, gaya bicara, gaya busana, serta tindakantindakan yang melekat pada dirinya sebagai mood of production yang sanggup membentuk dan menciptakan diri ketika melakukan interaksi. Instagram sebagai media visual mampu menghadirkan simbolsimbol tertentu sebagai alat memproduksi makna dari suatu identitas yang ingin disampaikan. Foto yang dihadirkan di Instagram merefleksikan kode-kode, nilainilai, dan keyakinan atas kebudayaan secara keseluruhan (Albertazzi, 2013:1). Instagram sebagai hasil teknologi yang berakulturasi dengan faktor-faktor ekonomi, sosial dan budaya menghadirkan leisure untuk para pengguna melakukan aktivitas secara bebas dalam hidup seperti hobi, rekreasi, menambah pengetahuan tentang seni dan budaya dan juga mengisi kegiatankegiatan aktual untuk mengisi waktu luang (Deaton, 1992:35). (Solikatun, Kartono, \& Demartoto, 2015:101), mengemukakan bahwa manusia berpraktik seperti dalam Instagram sebagai

"man is agent, he is, in his own apprehension, a center of unfolding impulsive activity; teleological activity. By force of his being such an agent, he is possessed of a taste for effective work and a distance for futile effort".

Pemikiran ini menjadikan manusia selalu berinteraksi, menariknya pada kenyaataan sehari-hari manusia dihadirkan mengikuti pranata sosial. Pranata sebagai pola-pola perilaku yang telah diciptakan, disepakati, dan kemudian diwajibkan oleh masyarakat. Semua pranata berfungsi sebagai sarana yang diharapkan memantapkan aktivitas, dimana fungsi ini tidak dipisahkan dari kuasa manusia atas masyarakatnya. Proses ini tidak berasal dari suatu hukum, melainkan dilandasi oleh sifat manusia untuk memikirkan keadaan dan tujuannya dan mengadaptasikan diri dengan baik. Proses perubahan sosial ini pun berlaku dalam dunia siber seperti Instagram yang notabene media sosial.

Foto dalam Instagram mempratikkan leisure dan juga bentuk intepretasi yang dimaksudkan dapat dikonsumsi khalayak. Bila dilihat dari aspek sosial, foto yang dihasilkan mempunyai makna sosial seperti Bourdieu kemukakan dalam "the sosial definition of Photography" pola perilaku masyarakat dalam menghasilkan foto terhegomoni oleh estetika popular yang sesungguhnya dibentuk sesuai dengan kategori norma-norma yang mengatur dunia secara umum. Bahkan, economicus symbol dihadirkan, seakan tubuh adalah sebuah tontonan (body as spectacle). Leisure yang dimaksud oleh Veblen adalah segala sesuatu atau aktivitas yang bukan milik dunia sehari-hari seperti kerja produktif dan dari kebiasaan pikiran yang workmanlike (Reynard \& Veblen, 1925:xxi), berarti waktu tidak produktif, pantang dari kerja (Veblen \& Banta, 2007:44-45).

Uniknya dalam dunia siber seperti pada Instagram, pengguna secara bersamaan bisa menjadi produsen sekaligus sebagai konsumen dari apa yang mereka hasilkan seperti halnya mengabadikan segala aktivitasnya melalui Instagram Stories. Fitur Instagram Stories adalah penambahan 
kepada profil pengguna mengenai fitur yang dapat merekam momen dalam aktivitas keseharian membuat rangkuman yang menunjukkan beberapa aktivitas menjadi satu cuplikan. Instagram stories menjadi ruang berkomunikasi visual yang sangat efektif untuk menceritakan aktifitas pemilik Instagram, sekaligus menggambarkan kehidupan penggunanya. Penggunaan Instagram stories yang lebih mengarah kepada gejala-gejala untuk menunjukkan status sosial serta gaya hidup pengguna. Penampilan Instagram Stories yang diunggah ada nilai lebih, momen yang dihadirkan memperlihatkan praktek pengguna dalam mengkonsumsi sesuatu seperti tempat-tempat tertentu (café, restoran, tempat wisata), fashion dengan berbagai macam desain, aktifitas pengguna, bahkan makanan yang mereka konsumsi. Hal-hal itu ditampilkan dalam feed pengguna untuk dikonsumsi oleh pengikutnya. Pemilik akun di Instagram ingin memperlihatkan kelasnya, dan bagian dari aktifitasnya sehari-hari. Instagram menghasilkan representasi pada penggunanya. Fenomena menampilkan tampilan Instagram Stories di ruang feed yang mereka miliki dapat dianggap representasi identitas menjadikan media yang mereka gunakan sebagai citra visual yang bisa mereka dapatkan. Pierre Bourdieu menekankan dalam "The Sosial Definition of Photography" bahwa pola perilaku masyarakat dalam menghasilkan visual terhegomoni oleh "estetika popular" yang sesungguhnya sudah dibentuk sesuai dengan norma-norma yang mengatur secara umum (Bourdieu, 1996).
Pengguna Instagram dalam kalangan kelas menengah yang kerap kali menebar unggahan Instagram Stories dalam feed dengan ingin memperlihatkan seperti apa yang dimiliki, Instagram Stories adalah fitur yang dimiliki Instagram dalam ruang-ruang media sosialnya. Dalam istilah Bourdieu, kelas menengah dalam beraktivitas di Instagram ingin memperlihatkan distinction berupaya mencari basis sistem klasifikasi yang menstruktur persepsi bagaimana dunia sosial dan menentukan objek kesenangan estetis dalam struktur kelas sosial seperti pada kalangan kelas menengah (Bourdieu \& Passeron, 1990: 66). Kelas terbentuk karena akumulasi golongan-golongan sosial dalam sebuah pranata dalam masyarakat yang ditentukan oleh posisi tertentu dalam suatu proses produksi. Kelas menengah sepertinya menikmati apa yang mereka produksi yang mereka unggah di Instagram Stories mereka di Instagram. Praktik gaya hidup yang ditawarkan dalam produk sehari-hari yang biasa mereka kerjakan antara lain kuliner, spa-salon kecantikan, fotografi, pertunjukkan, travelling, dll lalu diunggah di feed Instagram mereka. Lalu bagaimana kontruksi identitas melalui Instagram Stories yang dimiliki Instagram oleh kelas menengah ini, menjadi sebuah kajian yang menarik. Instagram Stories hadir dalam ruang diri pengguna di siber karena bagian manusia adalah aktor yang kreatif dari realitas sosialnya (Bungin, 2011:11). Manusia ingin mengkontruksi dirinya sesuai dengan keinginannya agar diterima secara sosial. Berger dalam tesisnya memperkenalkan mengenai 
kontruksi identitas yang smenggambarkan proses sosial melalui tindakan dan interaksi, dimana individu menciptakan secara terus menerus suatu realitas yang dimilikinya dan dialami bersama secara subjektif (Berger \& Luckmann, 1966: 29). Manusia dalam banyak hal memiliki kebebasan untuk bertindak, manusia secara aktif mengembangkan dirinya melalui responrespon terhadap stimulus dalam dunia kognitifnya. Individu manusia dipandang sebagai pencipta realitas sosial yang relatif bebas di dalam dunia sosialnya (Hirsch, 1982:142). Manusia mengembangkan seleranya dalam memutuskan sesuatu, Selera menurut Bourdieu,

"Taste is what brings together things and people that go together" (Bourdieu, 1984: 241).

Stuart Hall menjelaskan bahwa identitas dapat dilihat dalam dua pandangan, identitas budaya sebagai sebuah wujud (identity is being) dan identitas budaya sebagai sebuah proses yang dijalani (identity as becoming), identitas budaya dilihat sebagai satu kesatuan yang dimiliki bersama sebagai bentuk dasar atau asli individu dan berada dalam diri banyak orang yang mempunyai kesamaan sejarah dan leluhur (Hall, 1996:16). Barker mengutarakan identitas adalah soal kesamaan dan perbedaan tentang aspek personal dan sosial, tentang kesamaan individu dengan sejumlah orang dan apa yang membedakan individu dengan orang lain,

"identity is a cultural construction because the discursive resources that form the material for identity formation are cultural in character" (Barker, 2012:93).

Jadi, kontruksi identitas adalah kesadaran diri akan observasi dan penilaian konsep diri sebagai suatu kesatuan. Seseorang yang mempunyai perasaan identitas diri yang kuat akan memandang dirinya berbeda dengan orang lain. Individu yang memiliki identitas diri yang kuat akan memandang dirinya sebagai suatu kesatuan yang utuh dan terpisah dari orang lain dan selalu menjaga identitas diri dalam kondisi apapun walau sulit dan seringkali mengorbankan harga diri. Konstruksi identitas dapat dipahami sebagai persepsi orang lain dalam menilai diri seseorang melalui catatan atau tulisan. Kontruksi itu membentuk konsep diri self concept yang dapat diartikan sebagai Persepsi, keyakinan, perasaan, atau sikap seseorang tentang dirinya, Kualitas pemberian makna individu tentang dirinya, dan sistem pemaknaan individu dan pandangan orang lain tentang dirinya (Woodward, 2002:45)

Tujuan penelitian ini adalah memfokuskan pada praktik Instagram Stories dalam posisi kontruksi identitas dalam bingkai budaya siber di Instagram. Penelitian ini dalam lingkup kajian siber yang merupakan media yang sangat intens memasuki aktivitas manusia saat ini. Kajian mengenai budaya siber telah banyak dilakukan, seperti penelitian-penelitian sebelumnya yang bersumber pada digital, percepatan waktu inter aktivitas, sedangkan kontruksi identitas yang terbangun di media sosial, identitas budaya yang terbangun dalam dunia siber seperti hipertekstual, dispersal, virtualitas, dengan non-linearity, dan pemanfaatan jarak, modularity, remediasi, demasifikasi, asynchronicity, dan konvergensi (Hájek, 2013: 69-17) belum 
banyak diteliti lebih jauh. Budaya siber Digital yang dimaksudkan bagaimana bentuk data digital ini dapat menjadi lebih baik penggunaannya dari data analog dalam segi kecepatan dan dunia seakan nyata yang berbasis digital dan hanya dapat dilakukan dengan media komputer. Meski saat ini media siber juga sudah dapat diakses dengan teknologi mobile seperti smartphone sebagai pengembangan media komputer. Penelitian sebelumnya dalam bingkai budaya siber digital dalam smartphone (Setiansah \& Udasmoro, 2015), kehadiran smartphone dalam kehidupan sehari-hari bertransformasi dalam dunia digital menghadirkan perempuan urban dalam kultur baru yang berbeda dengan kultur bermedia sebelumnya. Kultur tersebut tidak hanya terkait dengan perangkat smartphone sendiri secara teknis sebagai sebuah artefak budaya, namun juga tentang proses pemaknaan dan serangkaian praktek penggunaannya. Analisis kritis dilakukan terhadap praktek penggunaan dan pemaknaan smartphone oleh perempuan urban beserta interseksi gender, kelas, dan agama yang terlibat di dalamnya yang menghasilkan smartphone sebagai media baru memiliki karakteristik yang khas dan berbeda dengan media komunikasi dan informasi sebelumnya. Smartphone telah menghadapkan perempuan pada beragam situasi yang mendua (ambivalence). Perempuan pengguna smartphone menyadari bahwa di samping memberikan peluang pemberdayaan, smartphone juga berpeluang melanggengkan konstruksi nilai dominan tentang perempuan. Smartphone dapat menjadi alat represi baru bagi perempuan. Penelitian praktek penggunaan dan pemaknaan smartphone oleh perempuan urban menghasilkan bahwa praktik budaya di dalam smartphone memiliki konsekuensi dan logika sendiri dalam pengoperasiannya dan pemaknaanya dalam aktivitas yang mereka jalani, subjek diposisikan sebagai pengguna.

Internet turut membentuk budaya baru, dalam kaitannya mengubah relasi pada konsumen yaitu mengkonsumsi dan pada saat yang sama memproduksi apa yang dikonsumsi. Sistem kapitalis mampu untuk menggali peluang dari tenaga kerja gratis dari prosumer dalam Web 2.0 ini. Kapitalisme mampu mengeksploitasi konsumen dan pada proses ini bahkan dapat menghasilkan profit yang lebih besar. Penelitian yang membahas tentang itu adalah penelitian "Sosial media, prosumption, and dispositives: New mechanisms of the construction of subjectivity" dari Melita Zajc (Zajc, 2015) yang mengungkapkan masalah media sosial dari perspektif prosumtion. Konsep prosumption dalam dunia digital telah menyatukan produksi dan konsumsi, dan menghasilkan kekhasan media sosial. Eksplorasi penelitian ini memperlihatkan harapan tentang potensi sosial penggabungan produksi dan konsumsi di media sosial dengan berfokus pada isu partisipasi pengguna dalam konsep komunikasi bermedia dalam dunia digital. Potensi yang diharapkan bagaimana konsumsi tidak terlalu diperhatikan, karena hanya mengeksplorasi produksi makna dalam berkomunikasi menggunakan media sosial, media sosialnya pun secara khusus 
tidak disebutkan secara spesifik. Oleh karena itu penelitian mengenai kontruksi identitas dalam media sosial (Instagram) dalam fitur Instagram stories adalah upaya untuk menentukan identitas "dalam gerak" individu dalam dunia siber.

\section{Metode Penelitian}

Penelitian di ruang siber memerlukan metode kualitatif yang khusus, ini dikarenakan banyaknya kekhasan dalam ruang siber yang membedakannya dengan praktik di ruang offline. Informan penelitian ini dipilih secara purposive dengan akun@putrilellyana (Atiqah Putri), @ rosakusumaazhar (Rosa Kusuma Azhar), @ herni_maryuliani (Herni maryuliani), @ taufik.mbantul (Taufik Ridwan), @ fajarmantoo (Fajarmanto). Informan ini adalah kelas menengah yang melakukan praktik konsumsi-produksi di ruang instagram. Kriteria pendidikan lulus perguruan Tinggi dan memiliki pekerjaan dan rata-rata pengeluaran untuk pribadi 1 juta keatas. Penelitian ini dilakukan mulai bulan Juli 2018 hingga April 2019 dengan Tabel.1 Informan Penelitian menggunakan Virtual etnografi melalui screenshot tiap informan mengunggah di instagram dan indepth interview bila ada unggahan dari informan yang perlu digali lebih agar dapat mendapatkan jawabanjawaban atas permasalahan penelitian, sejak pengumpulan data pertama dilakukan secara bersamaan peneliti juga melakukan analisa dengan data-data yang sudah diambil, "in ethnography, however, data and interpretation evolve together. Each informing the other" (Wolcott, 1990). Penelitian dilakukan menganalisa unggahanunggahan informan di ruang instagram karena kontruksi diri, liyan, dan struktur sosial yang dimediasi komputer menjadi sebuah fenomena yang unik bagi penelitian (Caliandro, 2018: 165).

Analisis data pada teknologi ruang siber mempunyai konsekuensi tersendiri, dalam ruang siber memungkinkan seseorang untuk mempraktikan budaya lama dengan caracara baru. Ruang siber sebagai sebuah bagian dari konteks budaya juga memungkinkan untuk dikaji dengan menggunakan etnografi.

\begin{tabular}{|c|c|c|c|c|}
\hline Nama & Usia & Pekerjaan & Domisili & Akun \\
\hline $\begin{array}{l}\text { Atiqah Putri } \\
\text { Lellyana }\end{array}$ & 26 thn & PNS & Yogyakarta & @putrilellyana \\
\hline Herni Maryuliani & 40 thn & $\begin{array}{l}\text { Pengusaha } \\
\text { Property }\end{array}$ & Yogyakarta & @ herni_maryuliani \\
\hline $\begin{array}{l}\text { Rosa Kusuma } \\
\text { Azhar }\end{array}$ & 40 thn & Broadcaster & Yogyakarta & @rosakusumaazhar \\
\hline Fajarmanto & 30 thn & $\begin{array}{l}\text { Model,Brand } \\
\text { Communication } \\
\text { Executive }\end{array}$ & Jakarta & @fajarmantoo \\
\hline Taufik Ridwan & 50 thn & $\begin{array}{c}\text { CEO Advertising } \\
\text { Agency }\end{array}$ & Yogyakarta & @taufik.mbantul \\
\hline
\end{tabular}

Sumber: Olahan Peneliti, 2019 
Dengan etnografi maka peneliti bisa melihat suatu wacana dari sudut pandang subjek yang diteliti (Saukko, 2003: 57). Etnografi juga akan berusaha melihat secara lebih luas mengenai realitas subjek yang dikaji. Etnografi bisa memberikan cara pandang baru mengenai pelabelan praktik budaya sesuatu, misalnya mengenai konsep resistensi (Saukko, 2003: 56).

Di lingkungan yang dimediasi secara teknologis, diri, other, dan struktur sosial sesungguhnya terbentuk melalui interaksi, yang dinegosiasikan secara bersama-sama dengan orang lain. Sejauh mana teknologi informasi dan komunikasi bisa memediasi identitas diri dengan relasi-relasi sosial seyogianya mengalihkan kita pada perhatian epistemology. Teknologi komunikasi yang baru ternyata menekankan ciri-ciri dialogis realitas sosial, dengan mengkaji ulang berbagai asumsi tradisional dan kategori penelitian sosial yang sebelumnya diterima bulat-bulat, bahkan Markham menyebutkan "The researcher has to conduct a multi-layered investigation of self and others while also collecting statistical and other kinds of data as are relevant to the particular context being examined" (Markham \& Baym, 2009: 67).

Kontruksi diri, other, dan struktur sosial yang dimediasi komputer menjadi sebuah fenomena unik, dalam dunia online, kontruksi identitas merupakan sebuah proses yang harus dirintis secara lebih sengaja atau sadar. Fenomena offline menjadikan tubuh bisa berjalan-jalan dan direspon oleh orang lain, dan dapat memberikan kacamata bagi pengguna untuk mengetahui diri atau self. Seperti yang diungkap Markham bahwa online adalah langkah pertama menuju eksistensi atau agar dikenali adalah penciptaan diskursus, entah dalam bentuk kata-kata, gambar grafis, suara (Markham \& Baym, 2011: 165). Sebagian besar lingkungan yang di mediasi komputer, proses ini membutuhkan pertukaran informasi yang lebih sadar karena manusia tidak hadir bersama di dalam ruang fisik yang sama, sedangkan aspek-aspek nonverbal proses tersebut sebagian besar, hilang. Prosesnya rumit dan kabur karena kita lazimnya didapatkan pengetahuan tentang diri secara otomatis tanpa banyak mempertimbangkan proses sosial dan interaktif yang menjadi alat untuk merundingkan diri dengan other di dalam konteks. Teks dipandang sebagai sarana yang ampuh untuk mengontrol, melalui penyuntingan, dan penghapusan mundur, cara mempresentasikan diri kepada liyan. Teks sangat penting bagi pemahaman oleh peneliti tentang persona online (Denzin, 2017). Konteks dunia siber yang diteliti ruang-ruang adalah di dalamnya, peneliti akan memakai metode etnografi virtual. Pendekatan etnografi virtual akan dilakukan karena penelitian ini obyeknya dalam ruang siber, sehingga cukup dapat memahami cara subjek berinteraksi dan bekerjasama melalui fenomena yang teramati dalam kehidupan sehari-hari baik dalam keseharian maupun dalam penggunaan instagram.

\section{Hasil Penelitian dan Pembahasan}

\section{Stories Instagram memberikan Identitas Status Sosial}

Instagram Stories adalah fitur yang diperuntukkan untuk pengguna Instagram agar lebih melekat dalam menggunakan Instagram diaktivitas kesehariannya. 


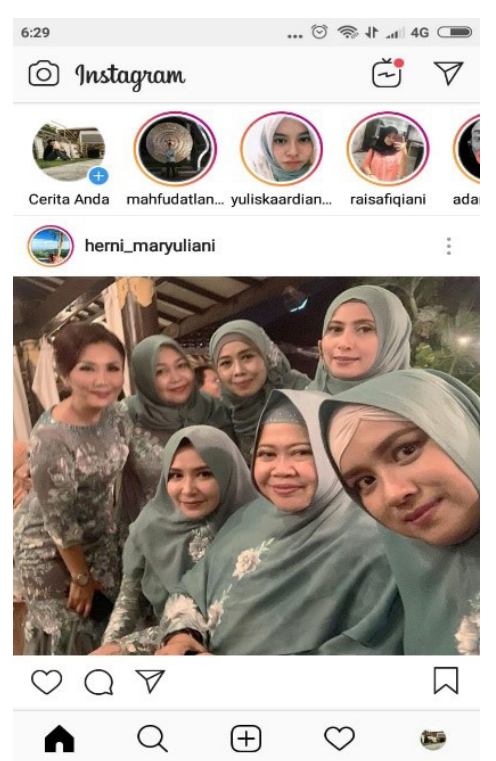

Gambar 1. Instagram Stories yang muncul diatas

Sumber: olahan peneliti, 2019

Instagram stories membagikan aktivitas yang "menarik" pengguna untuk diberitahukan pada pengguna lain. Fitur ini memungkinkan pengguna mengunggah foto dan video di Instagram dan ditempatkan dalam ruang sendiri (di sudut kiri display galeri pengguna Instagram).

Foto dan video yang dirasa memberikan kesan bermakna bagi pemilik akun dibagikan untuk dikomentari, walau unggahan itu hanyalah sesuatu yang sepele. Unggahan itu adalah bukti aktivitas mereka dalam keseharian, walaupun unggahan bisa merupakan foto dan video yang diambil sebelumnya. Fitur stories ini mengembangkan kenikmatannya dengan "Stories Highlights" dan "Stories Archive", keduanya berfungsi untuk menyimpan Stories yang telah diunggah. Stories Archive berfungsi untuk menyimpan seluruh stories yang telah dibuat dan semua stories yang diunggah akan secara otomatis tersimpan dalam arsip diprofilmu setelah 24 jam tampil di ruang jejaring Instagram. Stories Archive disajikan dalam urutan berdasarkan waktu postingan, dengan cerita terbaru di bagian atas, ditandai dengan tanggal (sesuai waktu unggahan). Setelah itu pengguna dapat memilih dan membagikan kembali ke bagian profil sebagai sebuah postingan, dikemudian hari.

Pada Stories Highlights, Instagram memberikan layanan memungkinkan pengguna untuk menyimpan Stories yang telah dibuat dan menyusunnya secara menarik sesuai keinginan dengan nama dan tema tertentu, seperti liburan, untuk ditampilkan pengguna di bagian bawah biografi profil pengguna di galeri Instagram. Konsep Karl Marx mengenai "means of production" dapat dikenali di sini (Fornas, Becker, Bjurstrom, \& Ganetz, 2007: 5), konsep ini terbentuk dalam pola di Instagram stories yang berfungsi sebagai alat untuk memproduksi interaksi dan penggunanya dapat mengkontrol atas proses tersebut. Informan melakukan "means of cultural production" sendiri, dengan cara Instagram betul-betul dipahami aturan dan fitur-fiturnya agar mereka dapat berstrategi mendapatkan respon dari pengguna Instagram lain berupa like, informan sebagai kelas menengah dapat mengontrolnya dengan selalu menjaga hasil unggahan.

Pengembang Instagram dalam hal ini Facebook Inc telah mempelajari kelas menengah di Indonesia. Kelas menengah di Indonesia memiliki konektivitas, dan pengetahuan dan ini menciptakan mentalitas baru pada sebagian besar penduduk Indonesia, yaitu mentalitas kelas menengah sebagai pasar yang potensial. Dari sisi 


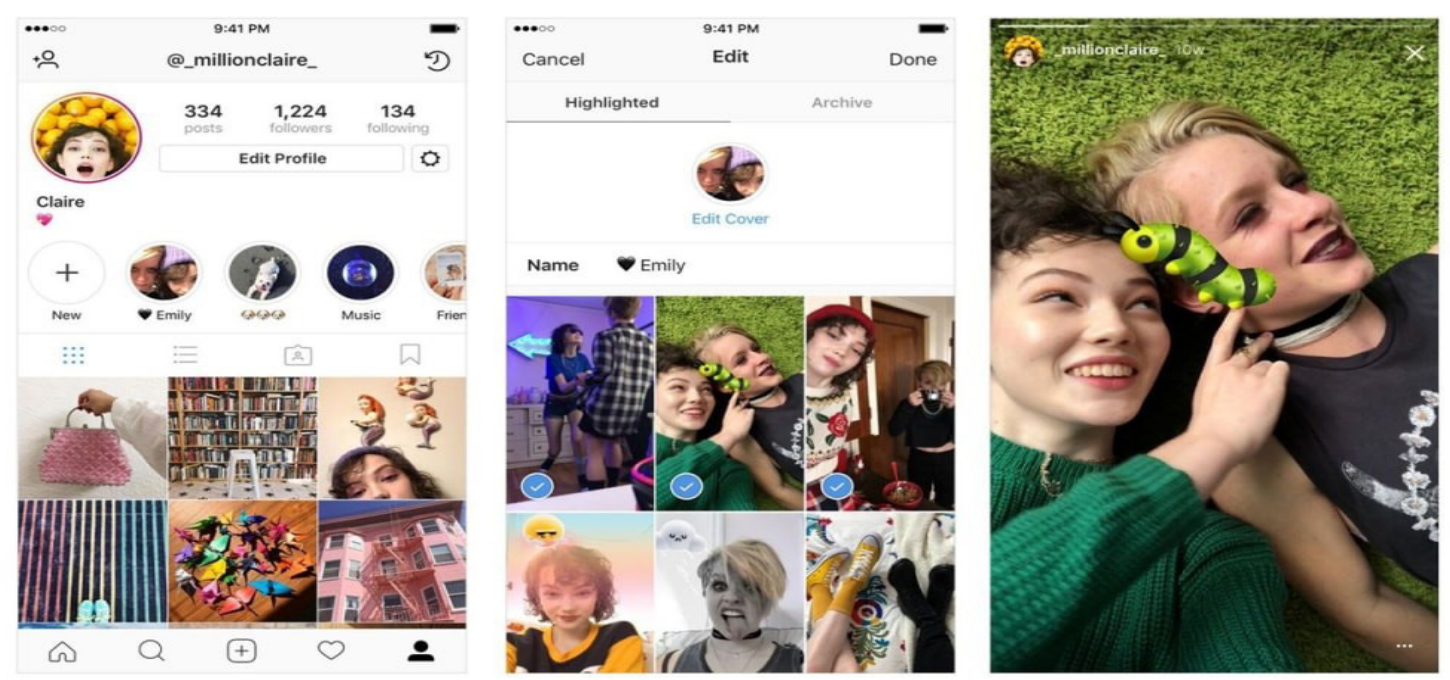

Gambar 2. Fasilitas Stories: Stories Archive dan Stories Highlight

Sumber: instagram.com/stories, 2019

positif, mentalitas ini membentuk seseorang lebih beradab, rasional, dan peduli terhadap lingkungan. Adapun dari sisi negatif, mentalitas ini membentuk seseorang menjadi cerewet, egois (selfish), dan penuntut (PEW Research Middle Class Institute, 2015). Relasi sosial siber yang ditawarkan dalam ruang Instagram adalah

" $m y$ feed-If there aren't any photos in your Feed, it's possible that you either aren't following anyone on Instagram or the people you're currently following".

Dimulai dari "kepemilikan pribadi" yang bisa dibanggakan berupa baru kemudian dibagikan ke orang lain, relasi ada digengamannya termediasi oleh perangkat seluler ditangan dan aplikasi yang ditanam. Instagram menghadirkan sebuah relasi dan di dalamnya termuat sistem simbolik, $I$ and Other yang ditata dalam dalam bentuk my feed dan follower.

Kemampuan bagi kelas menengah tidaklah berujung pada keinginan untuk barang komersil untuk dijual, tetapi mereka lebih suka orang lain memperhatikan mereka. Seperti yang oleh informan yang dalam keseharian seringkali mengunggah aktivitasnya dalam stories Instagram. Taufik mengungkapkan mengapa ia sering mengunggah aktivitasnya karena ia ingin diperhatikan.

"Mengunggah foto di Instagram stories, pertama karena ada kepuasannya... ada yang lihat, saya sedih misal berhari-hari yang nge-like cuma 5 orang, ini gila!", ujar Taufik. Bagi Taufik (wawancara 1 Juli 2019).

Berkenalan dengan stories sebagai hal yang baru bagi, sebelumnya Taufik hanya sibuk bermain Facebook, Taufik merasakan ada kepuasan secara emosional, bertemu dengan orang-orang yang satu selera, menjaga hubungan bahkan mendapatkan prestise sosial. Menurut Bourdieu, Taufik merasa mendapatkan "cultural capital" (Boudieu, 1993:7) dalam tiap unggahannya yang direspon. Taufik merasa ada hal-hal yang menarik dari unggahannya hingga direspon, ada kepuasan atas mobilitas sosial dalam masyarakat siber. Taufik merasa bila unggahannya banyak yang merespon ia seperti memiliki kawan banyak dan merasa apa yang diunggah mampu 
memberikan pengetahuan bagi temanteman Instagramnya.

"saya sangat suka unggahan saya di-copy paste, dan disebarkan ulang", ujar Taufik (wawancara 1 Juli 2019), merasa puas dan menikmati.

Begitupula Dedi, masih ingin memperlihatkan dunianya sebagai pekerja swasta (DJ) dan juga kehidupan nyata menyibukkan dirinya untuk mendalami agama, sesekali dalam stories tetap memperkenalkan Dedi yang lain yang keren dan bergaya dengan dandanan stylish juga unggah-unggahannya ketika memakai gamis dalam aktivitas di Pondok Pesantren. Informan memberikan kelasnya dalam ruang stories walau menahannya sedemikian rupa, consumer goods as communicators, as 'symbols of class bendabenda konsumen menjadi komunikator, sebagai symbol status kelas (Featherstone, Hepworth, \& Turner, 2017: 27). Informan ingin memberitahu pada followernya bahwa masih bisa "selow" atau santai dalam kesibukannya mengurus pesantren. Dedi ingin menunjukkan dirinya itu pribadi yang santai dalam aktivitas keseharian walau juga belajar agama dengan memperlihatkan apa yang dikonsumsi berupa hal-hal yang mendukung kelas menengah. Hasrat untuk menunjukkan suatu posisi atau status sosial yang lebih terpandang dalam suatu kelas dan pelarian bagi rutinitas Dedi karena merasa butuh untuk berekreasi, dalam hal ini Stories Instagram menjadi pemenuhan berselancar dan juga memproduksi konten di stories miliknya, leisure 'has become an escape from the pressures of the competitive '(Stebbins, 2009:3).

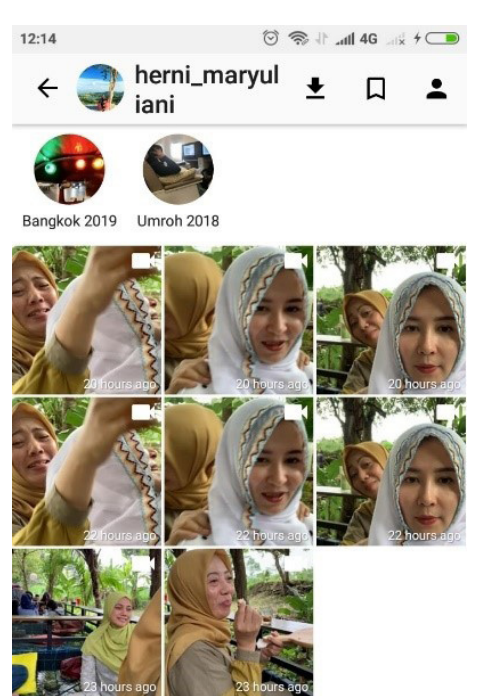

Gambar 3.Stories Akun@Herni_maryuliani

Sumber: Olahan Peneliti, 2019

Putri dan Herni juga selalu menyempatkan untuk mengunggah stories di akun Instagram. Unggahan stories dilakukan ketika berjalan-jalan dan di hari dan jamkerja. Herni menyatakan bahwa ketika unggahan ditanya peneliti memberitahu bahwa Heni seorang pengusaha dan seringkali kumpul dengan relasi di tempat-tempat semisal café, “tapi itu sebenarnya kerja”, Herni beralasan.

Putri pun menggunakan storiesnya untuk berkabar bahwa sedang menikmati hari dan santai, bahkan pun dapat membuat kata-kata mutiara dalam stories karena memang fitur ini dapat membuat teks yang terhias sedemikan rupa tak hanya Video pendek saja ataupun foto. Alasan Putri dengan mengunggah hal-hal yang bijak dalam storiesnya adalah:

"kalo yang di stories instagram tuh aku sukanya kayak gini harus menampilkan hal-hal yang bijak" ujarnya (wawancara 20 Juli 2019).

Selera membawa kepada kelas sosial di ranahnya masing-masing. Sehingga menurut Haryatmoko, kelas akan menempati posisinya masing masing yang ditentukan oleh dua 


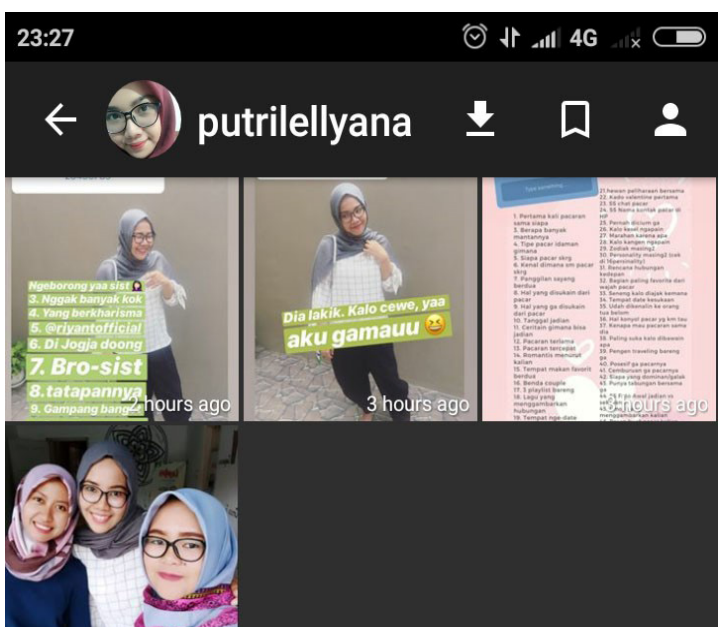

Gambar 4. Stories Akun@putrilellyana

Sumber: Olahan Peneliti, 2019

dimensi: pertama, menurut besarnya modal yang dimiliki dan kedua, sesuai dengan bobot komposisi keseluruhan modal mereka (Haryatmoko, n.d.), dan dalam ruang-ruang siber.

Rosa sebagai publik figur juga merasa Instagram memberikan pengalaman berelasi yang semakin luas, dan Rosa menikmatinya terlihat dari unggahannya hingga 29 Maret 2019 tercatat 368 postingan (peneliti mencatat hampir dalam seminggu sekali menghapus foto),

"Dulu saya ke medsos ngga terlalu gimana ya, terus lagi hobi, kalau kadang lagi suka terus ada sesuatu hal yang pengen saya publish, tapi kadang-kadang juga memberikan pesan juga sih ke beberapa kegiatan yang sifatnya siapa tahu memberi motivasi gitu", ujar Rosa (wawancara 12 November 2019).

Informan Dedi juga sependapat,

"saya upload saya make jubah, agar ada temen-temen atau orang lain yang melihat itu adem ayem atine, siapa tau seperti itu sebagai media dakwah, membuat orang tuh terinspirasi mendapat hidayah dari Allah juga, harapannya kayak gitu", ujarnya (wawancara 16 November 2019).

Foto-foto yang diunggah berdua pun sebenarnya hasil seleksi yang secara sadar mereka memiliki follower dan butuh respon

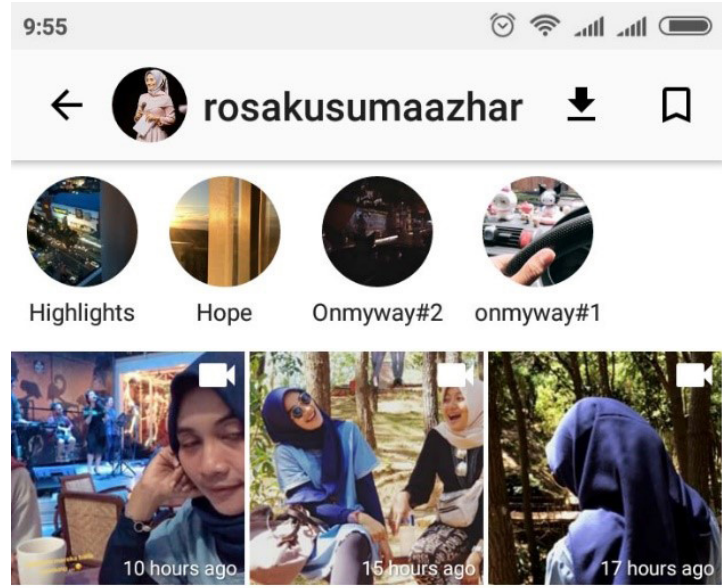

Gambar 5. Instagram Stories Rosa

Sumber: Olahan Peneliti, 2019

dengan tanda like. Foto yang diunggah pun ini masalah selera yang bagi Bourdieu adalah penanda status sosial. Selera adalah sesuatu yang tidak alamiah dan bukan pilihan bebas. Selera produksi kontruksi sosial yang dibentuk melalui kontruksi pendidikan dan pengasuhan,

"Taste is the basis of the mutual adjustment of all the features associated with a person, which the old aesthetic recommended for the sake of the mutual reinforcement they give one another", Bourdieu menegaskan selera adalah dasar penyesuaian kontruksi bersama, "Taste is what brings together things" (Bourdieu, 1984: 174).

Kelas menengah berkeinginan memperlihatkan segala aktivitasnya mempunyai perbedaan dengan kelas lainnya dan Bouerdieu ini adalah "selera". Selera adalah putusan estetis dari pebedaan kelas tidak sekedar kualitas yang dikonsumsi. Putusan estetis ini adalah kepentingan simbolik kelas menengah dalam memperlihatkan aktivitasnya.

Nilai estetis ini dirawat Instagram dengan menampilkan fitur-fitur yang mendukung nilai selera. Informan merasa ahli dalam membuat konten dalam Instagram stories (semua aplikasi dibuat human user sekali 
sehingga mudah) mengerti dan merasa paham tentang platform digital sehingga yakin dapat menampilkan gaya ekspresi dan komunikasi yang berselera. Aktivitas ini dilakukan informan Herni dan Fajar yang menceritakan aktivitasnya dalam Instagram stories live dalam arti secara real time, informan memproduksi bagaimana menikmati semua waktu yang mereka hasilkan dan tidak lupa untuk bersenangsenang dalam pekerjaannya karena dalam bekerja yang diperlihatkan dalam "stories live" bercerita bahwa memiliki kelas yang pekerjaan tidak semua orang memiliki. Seperti halnya di Perancis di tahun 1899, bagaimana kelas elitememperkenalkan status sosialnya dengan menggunakan korset dan sendok perak yang menggambarkan status posisi sosial dalam tiap-tiap pertemuan, bila sekarang cukup dengan memperlihatkan secara mudah dan live melalui stories yang dimiliki Instagram.

Informan dalam Instagram seperti pekerja pengetahuan dalam masyarakat pengetahuan yang dikemukakan Peter Drucker (Bolisani \& Bratianu, 2017), menyebutkan bahwa dalam masyarakat baru faktor-faktor produksi yang dominan dan menentukan bukan lagi modal, tanah, atau tenaga kerja, tetapi pengetahuan (Raharso, 2011). Oleh karena itu, kapabilitas untuk mencipta, menyimpan, menyebarkan, mengelola, dan mengendalikan akses pada pengetahuan akan menjadi sesuatu yang krusial bagi kinerja seseorang. Informan yang menjadi pengguna dan memiliki akun di Instagram, ketika beraktivitas menjadi pekerja estetika dalam "masyarakat
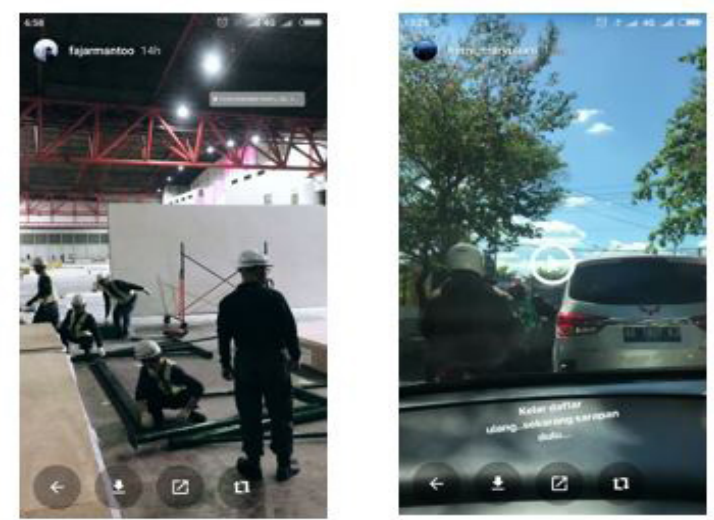

Gambar 6. Instagram Stories live Fajar dan Herni Sumber: Olahan Peneliti, 2019

berestetika" (masyarakat barang dan layanan konsumen yang canggih secara estetika). Dalam masyarakat estetika, produksi dan penyajian gambar-gambar indah, pengalaman, gaya, dan desain interaksi pengguna merupakan pusat fungsi ekonomi dan sosialnya. Masyarakat estetika menghargai desainer ruang, desainer pengalaman pengguna, arsitek, fotografer, model, stylist dan profesional desain dan media lainnya, serta individu yang terampil menggunakan Instagram, jejaring sosial lainnya dan platform blog, dan pengeditan media, kreasi, dan alat analisis. "Menggunakan" dalam konteks ini mengacu pada menciptakan konten yang sukses, mempromosikan konten ini, berkomunikasi dengan pengikut, dan mencapai tujuan yang diinginkan. Masyarakat estetika juga merupakan tempat di mana masyarakat media sosial muncul dan mempertahankan diri melalui pilihan dan pengalaman estetika. Seperti yang diutarakan Michel Maffesoli masyarakat urban adalah masyarakat yang itu mengacu pada suasana tertentu, keadaan pikiran, yang diungkapkan melalui gaya hidup dengan penampilan dan 
bentuk (Maffesoli, 1996: 25). Instagram membekali pengguna yang menggunakan aplikasinya dengan estetika yang dapay digunakan dalam fitur yang disertakan di "Instagram Stories", dan banyak filter yang memperindah penggunanya yang dapat menjadikan masyarakat urban. Ada pesan yang dilepas dalam unggahan-unggahan di Instagram oleh Instagramism:

"If in the modern societies carefully constructed aesthetic lifestyles were the privilege of the rich, today they are available to all who use Instagram"(Maffesoli, 1996:138),

lifestyle dapat disajikan dengan Informan melaluifoto-fotodanceritayang diunggahnya dengan Instagram. Penunjukkan apa yang diproduksi berupa pilihan selera bagi Fajar dan Herni yang dipertunjukkan di stories adalah selera sebagai senjata dalam berkompetisi, Fajar sebagai pekerja swasta di bidang kreatif dan Herni sebagai pengusaha property memperlihatkan bahwa dalam bekerja ada selera "senangsenang". Informan menikmati hidup dengan mengonsumsi waktu luang yang selalu ada dalam aktivitas. Kompetisi tersebut berlangsung antar pribadi, antara seseorang dengan orang lain. Jika dalam masyarakat tradisional, keperkasaan seseorang sangat dihargai, sedangkan dalam masyarakat modern, penghargaan diletakkan atas dasar selera yang konsumsi dan di dunia siber bisa mereka produksi secara visual.

\section{Instagram Stories, Identitas Sosial yang Ditanam}

Foto yang dihadirkan di Instagram merefleksikan kode-kode, nilai-nilai, dan keyakinan atas kebudayaan secara keseluruhan (Lukac et al., 2012). Pengguna dalam dunia siber secara bebas dapat membuat informasi yang benar-benar baru mengenai dirinya di dunia ini. Bahkan menurut Monika Bakke,

"Disregarding anatomy, humans have the possibility to embody various cultural genders, By doing so they gain a multiple sosial identity. The assumption that one body corresponds to one cultural..." (Ensslin \& Muse, 2011b: 81).

Individu sudah dapat membuat identitas baru tentang dirinya kepada dunia baru, Identitas tersebut tentunya sulit untuk dibuktikan kenyataannya (Green, 2010: 130). Walau sulit dibuktikkan tapi mampu mengkonstruksi identitas sosial, bagaimana orang lain memahami diri yang membagi identitasnya di dunia siber karena dalam dunia siber akun dengan akun bagaikan sebuah jaring saling mengkait, bukan hanya tubuh dan keadaan fisik tetapi lingkungan sekitarnya juga. European Data Protection Directive menjelaskan bahwa,

Any information relating to an identified or identifiable natural person ('data subject'); an identifiable person is one who can be identified, directly or indirectly, in particular by reference to an identification number or to one or more factors specific to his physical, physiological, mental, economic, cultural or sosial identity (Dahan \& Gelb, 2016:91)

Diri dalam dunia siber adalah "personal data" semua jenis kelamin, ciri fisik, pengalaman diri, latar belakang budaya, pendidikan dan semua atribut yang melekat pada diri seseorang. Informan Herni, Rosa, Putri, Nana, Fajar, Taufik, melakukan itu semua, ingin menjadikan diri dalam kategori kelas yang memang diharapkan. Peneliti mencatat unggahan yang ada di stories informan dimulai di awal September 2018, benar-benar memperhatikan siapa dan lingkungan yang menyatu dengan dirinya. 
Chris Barker menjelaskan bahwa, identitas ini harus berdasarkan pada pemahaman tindakan dalam konteks sosialnya, "soal apa yang kamu miliki secara bersamasama dengan beberapa orang dan apa yang membedakan kita dengan orang lain" (Barker, 2012:93)

Dalam stories highlight yang simpan di ruang stories berupa rekaman-rekaman aktivitas dalam kegiatan informan berupa hal-hal yang menarik bagian dari conspicuous consumption (konsumsi yang mencolok) pertontonkan kepada orang lain. Visual-visual yang disimpan itu untuk menegaskan gengsi dan status informanyang memiliki gaya hidup sebagai kelas menengah punya keleluasan waktu untuk dihabiskan.

Mahfud menambahkan menanam stories highlight berupa perjalan ia dalam menelusuri alam Indonesia dalam bahasanya perjalanan sufi, stories highlight miliknya sudah ditanam ketika peneliti menelusuri jejak digital Mahfud dan selalu ada yang baru diganti. Stories highlight

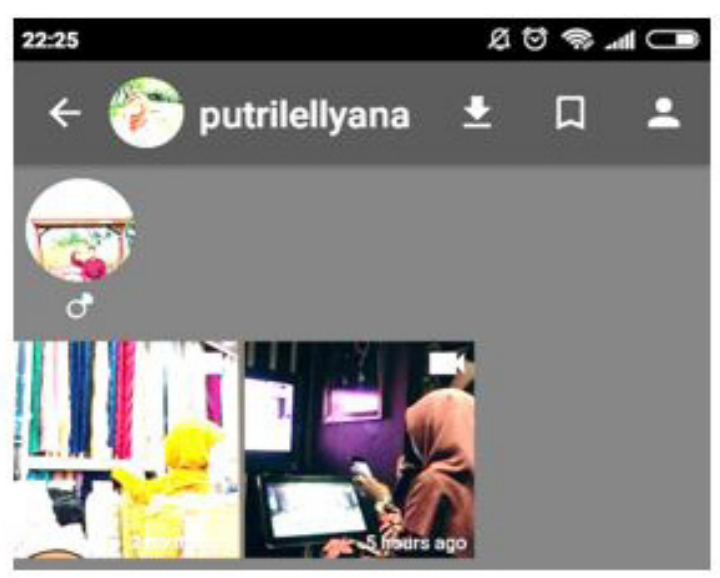

Herni perjalanan ia ke Bangkok dan juga Umrohnya, stories highlight ini pun berganti karena sebelumnya ada yang berupa foto hobi Informan berjalan-jalan naik sepeda, kumpul-kumpul dengan teman-temannya, keluarga di berbagai tempat. Putri pun demikian, banyak menampilkan jalanjalannya di berbagai café dan ruang-ruang wisata. Taufik menampilkan perjalanan karier dan aktivitas agama tampilkan di stories highlight yang ditampilkan khusus.

Di dalam stories highlight informan menanam atribut berada di ruang sosial mana mereka merupakan cara melanggengkan di ruang kelas mana berada yang semakin memperkuat identitas sosial mereka. Follower yang menjadi temanteman informan mengetahui dan "merasa" mengetahui latar belakang informan dilihat dari sajian visual yang informan tanam di stories highlight, apa yang Informan konsumsi, di mana informan, apa yang dikenakan bisa Follower akses secara video maupun unggahan foto kapanpun ketika follower menyambangi

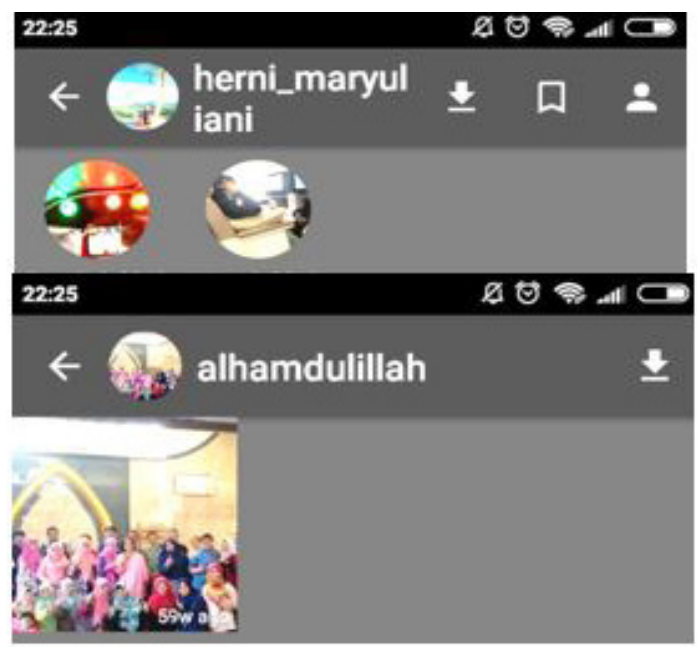

Gambar 7. Instagram Stories Highlight herni_maryuliani,@putrilellyana@taufikmbantul Sumber: Olahan Peneliti, 2019 
akun Informan. Conspicuous consumption maupun leisure Informan tanam dengan mudah untuk identitas sosial yang bagikan tidak hanya mengkonsumsi tetapi juga memproduksi yang dapat dikonsumsi oleh follower. Aktivitas yang ditanam dan dapat dikonsumsi follower menjadi hal yang unik dan dapat mengikatkan Informan dengan kelas sosialnya,

"Setiap orang berusaha membangun identitas sosial (sosial Identity), sebuah representasi diri yang membantu mengkonseptualisasikan dan mengevaluasi diri, sehingga mengetahui siapa diri (self) dan siapa orang lain (others)"'(Baron \& Branscombe, 2012: 116).

Bahkan, Tajfel menambahkan,

"we can perceive ourselves differently at any given moment in time, depending on where we are on" (Baron \& Branscombe, 2012:114).

Dalam ruang siber seperti Instagram Informan dapat dengan mudah mengubah apa yang diletakan-tanam di stories highlight karena identitas yang Informan hadirkan disadari Informan memberi konstruk terhadap bagaimana memandang diri dan respon orang lain terhadap Informan. Jadi, jika Informan adalah wanita maka unggahan foto atau video memperlihatkan atribut yang Informan yakini memperlihatkan berbeda dari wanita lain, misal hangat dan penuh perhatian. Atribut diyakini membedakan dari wanita lain. Demikian juga, jika lakilaki, gaya dalam memperlihatkan mandiri dan kuat akan diyakini dibedakan oleh Informan Taufik, Fajar, Dedi dengan gaya sendiri dan juga kelas sosial berada. Seberapa penting konten yang ingin informan bagikan, mengubah cara informan mendefinisikan diri. Hal ini terlihat dalam sering berubah-ubah stories highlight yang disimpan, dihapus, ditanam atau ditampilkan dalam kurun waktu tertentu menyesuaikan keinginan Informan dalam membagi stories highlight. Misalnya saja Taufik membagikan stories mengenai pekerjaan yang menyangkut relasi dan agama untuk menjadi titik fokus yang ingin dihadirkan di stories highlight,

"saya ingin mempengaruhi orang lain... juga orang lain sering mengikuti dakwah saya, saya dulu disebut Ustad Blacberry loh mas" ujar Taufik (wawancara 1 Juli 2019),

sehingga unggahan yang ia tanam dalam stories highlight pun selalu relasi dan keagamaan. Begitupula Fajar, menampilkan pekerjaan dan kesibukan ia beraktivitas, alasannya

"Aku pengen kasih tahu aku kerja apa sekarang mas ke teman-teman, sama... kali-kali aja ada kolega yang ngajakin bisnis" (wawancara 12 Juli 2019).

Identitas sosial yang ditanam informan dalam stories highlight yang terbaca dalam jejaring sosial yang Informan miliki, dalam kurun waktu tertentu sering dihapus dan diunggah yang baru, ini berlaku pada semua informan. Menurut Robert A. Baron ini adalah identitas yang kesemuanya dapat dibenarkan sebagai alasan "selves" dapat diterima dalam kelas sosial yang diharapkan,

"All of these could be correct portraits of the self and accurately predict behavior, depending on the context and comparison dimension" (Baron \& Branscombe, 2012:115).

Identitas sosial bisa saja dicitrakan secara koheren dengan diri Informan karena yang mendefinisikan adalah Informan sesuai keinginannya, sambil mengakui bahwa Informan dapat mendefinisikan diri sendiri dengan mendefinisikan perilaku yang berbeda dalam situasi berbeda pula. 
Ini dapat terjadi baik karena domain di mana kita melihat diri kita sebagai tidak konsisten dianggap relatif tidak penting, atau tidak menonjol ketika kita menganggap diri kita dalam hal identitas tertentu. Menampilkan diri di ruang stories highlight tidak hanya sebagai bagian ingin diterima secara sosial, tetapi juga Informan memaknai ini adalah perayaan rekreatif sekaligus mempertegas perbedaan kelas sosial Informan. Cara Informan memilih foto atau video yang ditampilkan di stories highlight merefleksikan gaya hidup Informan dari kelas mana mereka berasal, dengan tidak membiarkan momen atau peristiwa yang Informan jalani berlalu begitu saja.

Seperti gaya hidup kelas borjuis di Amerika Serikat yang dianggap borjuis, konsumtif, dan sama sekali tidak produktif, di era siber ini Informan memperlihatkan bahwa mereka bisa produktif di ruang Instagram. Fajar menampilkan diri di stories highlight dengan bersenangsenang tetapi juga dapat membangun relasi dan pekerjaan. Taufik dengan usaha umroh hajinya ditampilkan dalam stories highlight untuk menjaring relasi dan klien. Herni dengan usaha propertinya yang sesekali ia tampilkan dalam latar belakang aktivitasnya, dan kesemua itu menjaring relasi dan bisnis tidak hanya sekedar memanfaatkan waktu luang dan berekreasi dengan fitur-fitur di Instagram yang menghabiskan waktu. Kelas menengah berinteraksi dalam Instagram tak hanya memperlihatkan identitas sosial mereka saja tetapi sadar relasi yang mereka miliki dapat mereka sentuh dalam ruang Instagram.
Mengutip istilah "Instinct of workmanship" (Suyanto, 2017: 258), sehingga yang terjadi walau Informan melakukan conspicuous consumption maupun leisure, Informan mempunyai naluri untuk bekerja dalam ruang Instagram untuk menghasilkan kepuasan bagi diri, menambah penghasilan dan menyadari keberhasilan adalah alat ukur dihormati secara sosial oleh kelas menengah. Konsumsi adalah bagian yang memang selalu menjadi aktivitas di dunia nyata, dan memang juga diperlihatkan dalam dunia online. Aktivitas itu memberikan dan menekankan bahwa kelas menengah memiliki selera dalam membagi kehidupan dan aktivitasnya, lebih-lebih di media sosial seperti instagram.

\section{Simpulan}

Informan sebagai kelas menengah hidup dalam kehidupan yang sangat mengkonsumsi nilai kebutuhan duniawi yang lebih mengedepankan pada kesenangan dan kenikmatan, mengarah pada melakukan konsumsi yang berlebih (perilaku konsumtif) diperlihatkan dalam presentasi di instagram stories informan. Praktik bersenang-senang dan ditampilkan pada follower instagram informan merupakan bagian dari kontruksi identitas Informan yang memperlihatkan roh animalistik dan memperkuat hasrat barbarian untuk mendominasi sehingga menjadikan definisi bahwa beda dari temanteman lain, ada nilai yang ingin dibedakan dalam instagram stories. Gaya hidup yang Informan perlihatkan sebenarnya sedang mempertunjukkan nilai-nilai tersendiri yang berhubungan dengan waktu dan uang. Menghabiskan waktu dengan 
bersenang-senang (leisure) adalah bagian mempertotonkan kelas informan dengan mengeluarkan uang yang tidak sedikit. Kelompok yang dikategorikan dalam kelas menengah menjadikan gaya hidup bagian dari diri di dalam aktivitas. Informan berkegiatan demi meningkatkan status sosial, entah itu sadar ataupun tidak sadar, berlomba-lomba di dalam memanfaatkan barang yang dinilai bernilai tinggi. Aktivitas memperlihatkan kepada orang lain sangat difasilitasi oleh instagram dengan fiturfitur yang yang diciptakan untuk tetap menggunakan instagram. Fitur-fitur itu menjadi ruang perayaan memperlihatkan bahwa kelas menengah pun memiliki selera dalam menentukan apa yang dijkonsumsi dan selera apa yang mereka sehingga dapat membuktikkan mereka berada di kelas yang memilik perbedaan tersendiri.

\section{Daftar Pustaka}

Albertazzi, Liliana. (2013). Shape of Forms. Dordrecht: Kluwer Academic Publishers.

Barker, C. (2012). The SAGE Dictionary of Cultural Studies. The SAGE Dictionary of Cultural Studies. https://doi. org/10.4135/9781446221280

Baron, R. A., \& Branscombe, N. R. (2012). Social Psychology. Boston: Pearson.

Berger, P. L., \& Luckmann, T. (1966). The Social Construction of Reality. New York: Penguin Books.

Boellstorff, T., Nardi, B., Pearce, C., \& Taylor, T. L. (2012). Ethnography and virtual worlds: A handbook of method. Journal of Broadcasting and Electronic Media (Vol. 40). https://doi. org/10.1080/08838159609364336
Bolisani, E., \& Bratianu, C. (2017). The Emergence of Knowledge Management. The age of discontinuity: Guidelines to our changing society (pp. 23-47). https:// doi.org/10.1007/978-3-319-60657-6_7

Boudieu, P. (1993). The Field of Cultural Production. Columbia University Press.

Boudieu, P. (1996). Photography: A Middle Brow Art. Cambridge: Blackwell Publishing Ltd.

Bourdieu, P. (1984). Distinction, A Social Critique of the Judgement of Taste. USA: Harvard University Press.

Bourdieu, P., \& Passeron, J. C. (1990). Theory, Culture and Society. London: SAGE Publications.

Bungin, B. (2011). Kontruksi Sosial Media Massa. Jakarta: Prenada Media Grup.

Caliandro, A. (2018). Digital Methods for Ethnography: Analytical Concepts for Ethnographers Exploring Social Media Environments. Journal of Contemporary Ethnography, 47(5), 551-578. https:// doi.org/10.1177/0891241617702960

Dahan, M., \& Gelb, A. (2016). Digital identity. Deaton, A. (1992). Understanding Consumption. New York: Oxford University Press.

Denzin, N. K. (2017). Critical Qualitative Inquiry. https://doi. org/10.1177/1077800416681864

Ensslin, A., \& Muse, E. (2011). Creating Second Lives. https://doi. org/10.4324/9780203828571

Featherstone, M., Hepworth, M., \& Turner, B. S. (2017). The Body: Social Process and Cultural Theory. In SAGE Publications. London: Sage Publicatio Inc.

Fornas, J., Becker, K., Bjurstrom, E., \& Ganetz, H. (2007). Consuming Media: Communication, Shopping and Everyday 
Life. Oxford: Berg Publishers.

Hájek, R.(2013). James Curran, NatalieFenton, and Des Freedman, Misunderstanding the Internet. 7, 2012-2014.

Hall, S.(1996). Cultural Identityand Diaspora. https://doi.org/10.1186/1475-925X-8-28

Haryatmoko. (n.d.). Menyingkap Kepalsuan Budaya Penguasa. Basis No. 11-12.

Hirsch, E. (1982). The Concept of Identity. New York: Oxford University Press.

Lukac, R., Stanco, F., Battiato, S., Gallo, G., Lezoray, O., \& Grady, L. (2012). Digital Imaging and Computer Vision Series Digital Imaging for Cultural Heritage Preservation: Analysis, Restoration, and Reconstruction of Ancient Artworks, Image Processing and Analysis with Graphs: Theory and Practice.

Maffesoli, M. (1996). THE TIME OF THE TRIBES: The Decline of Individualism in Mass Society. London: Sage Publication.

Markham, A. N., \& Baym, N. K. (2009). Internet Inquiry. Singapore.

PEW Research Middle Class Institute, 2015

Raharso, S. (2011). Mengelola Pekerja Pengetahuan. Jurnal Administrasi Bisnis, 7(1), 38-48.

Reynard, H., \& Veblen, T. (1925). The Theory of the Leisure Class. The Economic Journal, 35(139), 445. https://doi. org $/ 10.2307 / 2223225$

Saukko, P. (2003). Doing Research in Cultural Studies. London: SAGE Publications.

Setiansah, M., \& Udasmoro, W. (2015). Politik Identitas Perempuan Pengguna
Smartphone: Negosiasi, Apropriasi dan Resistensi Perempuan Dalam Dunia Serba Ambivalen. Jurnal Ilmu Komunikasi, 13(2), 183-192.

Shapiro, A. (1999). The Internet. In Foreign Policy. https://doi. org/10.1097/00000542-19981000000024

Solikatun, Kartono, D. T., \& Demartoto, A. (2015). Perilaku Konsumsi Kopi Sebagai Budaya Masyarakat Konsumsi: Studi Fenomenologi Pada Peminum Kopi Di Kedai Kopi Kota Semarang. Jurnal Analisa Sosiologi, 4(1), 60-74. https:// doi.org/10.20961/JAS.V4I1.17410

Stebbins, R. A. (2009). Leisure and Consumption Common Ground/ Separate Worlds. New York: Palgrave Macmillan.

Suyanto, B. (2017). Sosiologi Ekonomi: Kapitalisme dan Konsumsi di Era Masyarakat Post-Modernisme. Jakarta: Prenada Media.

Veblen, T., \& Banta, M. (2007). The Theory of The Leisure Class.

Wolcott, H. F. (1990). Making A Study "More Ethnographic." Journal of Contemporary Ethnography, 19(1), 44-72.

Woodward, K. (2002). Understanding Identity. London: Arnold Publishers.

Zajc, M. (2015). Social media, prosumption, and dispositives: New mechanisms of the construction of subjectivity. Journal of Consumer Culture, 15(1), 28-47. https:// doi.org/10.1177/1469540513493201 